\title{
The economic cost of losing native pollinator species for orchard production
}

\author{
Néstor Pérez-Méndez ${ }^{1,2}$ (D) | Georg K. S. Andersson ${ }^{1,3}$ (D) | Fabrice Requier ${ }^{1,4}$ (D) | \\ Juliana Hipólito $^{1,5}$ (D) | Marcelo A. Aizen ${ }^{6}$ (D) | Carolina L. Morales ${ }^{6}$ (D) | Nancy García ${ }^{7}$ | \\ Gerardo P. Gennari ${ }^{8}$ (i) | Lucas A. Garibaldi ${ }^{1,9}$ (D)
}

\begin{abstract}
${ }^{1}$ Instituto de Investigaciones en Recursos Naturales, Agroecología y Desarrollo Rural, Universidad Nacional de Río Negro, San Carlos de Bariloche, Río Negro, Argentina; ${ }^{2}$ IRTA, Estació Experimental de I'Ebre, Tarragona, Spain; ${ }^{3}$ Centre for Environmental and Climate Research, Lund University, Lund, Sweden; ${ }^{4}$ Evolution Génome Comportement et Ecologie, CNRS, IRD, Université Paris-Sud, Université Paris-Saclay, Paris, France; ${ }^{5}$ Instituto Nacional de Pesquisas da Amazônia - INPA, Amazonas, Manaus, Brazil; ${ }^{6}$ Grupo de Ecología de la Polinización, INIBIOMA, Universidad Nacional del Comahue and Consejo Nacional de Investigaciones Científicas y Técnicas (CONICET), San Carlos de Bariloche, Argentina; ${ }^{7}$ Centro Pyme Adeneu, Agencia de desarrollo económico del Neuquén, Neuquén, Argentina; ${ }^{8}$ Estación Experimental Agropecuaria Famaillá - Programa Nacional de Apicultura (PROAPI), Instituto Nacional de Tecnología Agropecuaria (INTA), Tucumán, Argentina and ${ }^{9}$ Instituto de Investigaciones en Recursos Naturales, Agroecología y Desarrollo Rural, Consejo Nacional de Investigaciones Científicas y Técnicas, San Carlos de Bariloche, Río Negro, Argentina
\end{abstract}

\section{Correspondence}

Néstor Pérez-Méndez

Email: nestorperezmendez@gmail.com

Georg K. S. Andersson

Email: gandersson@unrn.edu.ar

\section{Funding information}

National Fund for Research, Grant/Award Number: PICT 2015-2333; Universidad Nacional de Río Negro, Grant/Award Number: PI 40-B-399 and PI 40-B-567;

Consejo Nacional de Investigaciones Científicas y Técnicas, Grant/Award Number: PDTS, Res 298/14, Exp 8383/13

Handling Editor: Tim Diekötter

\section{Abstract}

1. The alarming loss of pollinator diversity world-wide can reduce the productivity of pollinator-dependent crops, which could have economic impacts. However, it is unclear to what extent the loss of a key native pollinator species affects crop production and farmer's profits.

2. By experimentally manipulating the presence of colonies of a native bumblebee species Bombus pauloensis in eight apple orchards in South Argentina, we evaluated the impact of losing natural populations of a key native pollinator group on (a) crop yield, (b) pollination quality, and (c) farmer's profit. To do so, we performed a factorial experiment of pollinator exclusion (yes/no) and hand pollination (yes/no).

3. Our results showed that biotic pollination increased ripe fruit set by $13 \%$ when compared to non-biotic pollination. Additionally, fruit set and the number of fruits per apple tree was reduced by less than a half in those orchards where bumblebees were absent, even when honeybees were present at high densities. Consequently, farmer's profit was 2.4-fold lower in farms lacking bumblebees than in farms hosting both pollinator species. The pollination experiment further suggested that the benefits of bumblebees could be mediated by improved pollen quality rather than quantity.

4. Synthesis and applications. This study highlights the pervasive consequences of losing key pollinator functional groups, such as bumblebees, for apple production and local economies. Adopting pollinator-friendly practices such as minimizing the use of synthetic inputs or restoring/maintaining semi-natural habitats at farm and landscape scales, will have the double advantage of promoting biodiversity conservation, and increasing crop productivity and profitability for local farmers. Yet because the implementation of these practices can take time to deliver results, 
the management of native pollinator species can be a provisional complementary strategy to increase economic profitability of apple growers in the short term.

\section{KEYWORDS}

apple, bumblebees, crop pollination, crop yield, honeybees, orchard, profitability, sustainable agriculture

\section{1 | INTRODUCTION}

Animal pollinators play a key role in agroecosystems, contributing to increased yield of most crops world-wide (Aizen, Garibaldi, Cunningham, \& Klein, 2009; Klein et al., 2007). Yet intensification of farming practices is threatening pollinator and pollination services (Potts et al. 2010; Potts, Imperatriz-Fonseca, Ngo, Biesmeijer, et al., 2016) at the same time that demand on pollinator-dependent crops is continuously growing (Aizen \& Harder, 2009). Habitat loss, landscape fragmentation and overuse of agrochemicals are all important drivers of pollinator decline in agricultural landscapes, along with the introduction of exotic species and pathogens (González-Varo et al., 2013; Goulson, Nicholls, Botías, \& Rotheray, 2015; Vanbergen et al., 2013). Given the importance of pollinators in food production, decrease of pollination services might generate scenarios of scarcity, or low diversity of food (Potts, Imperatriz-Fonseca, Ngo, Aizen, et al., 2016). Therefore, a transition to more sustainable production systems, and a better understanding of the role of managed and wild pollinators for food production must be prioritized (Garibaldi, Requier, Rollin, \& Andersson, 2017).

A wide diversity of wild bee species are recognized as highly efficient pollinators for crops (Garibaldi et al., 2011, 2013; but see also Rader et al., 2016). Among the latter, large-sized species such as bumblebees (Apoidea) are disproportionally efficient as pollinators of both wild and cultivated plant species (e.g. Javorek, Mackenzie, \& Vander Kloet, 2002). These large-sized species are also more sensitive to environmental changes and intensive farming practices (Rundlöf et al., 2015). Bumblebees in particular have suffered a general decline world-wide (Arbetman, Gleiser, Morales, Williams, \& Aizen, 2017; Bommarco, Lundin, Smith, \& Rundlöf, 2012). In Latin America (LA), wild bee diversity, including several species of native bumblebees (e.g. Bombus dahlbomii, Guérin-Méneville, 1835; B. pauloensis, Friese, 1913), has declined dramatically, especially with the introduction of the European bumblebees B. terrestris (Linnaeus, 1978) and B. ruderatus (Fabricius, 1775) (Morales, Arbetman, Cameron, \& Aizen, 2013), the use of agrochemicals and the transformation of landscapes by intensive agriculture expansion (e.g. Breno et al., 2009; Martins \& Melo, 2010).

To satisfy the pollination demand in the absence of native bumblebees and other wild pollinators that provide efficient and sustainable crop pollination services, farmers routinely practice massive supplementations of managed pollinators such as the Western honeybee Apis mellifera L. (Aebi et al., 2012; Geslin, Gauzens, et al., 2017; Goodwin, Cox, Taylor, Evans, \& McBrydie, 2011; Rucker, Thurman, $\&$ Burgett, 2012). However, this practice might not optimize crop yield as high densities of honeybees at the farm level can result in undesirable outcomes (Rollin \& Garibaldi, 2019). For example, high visit frequency, that may result from an oversupply of managed bees or from extremely high abundances reached by invasive species, can limit crop production as a result of increased flower style damage (e.g. Sáez, Morales, Ramos, \& Aizen, 2014) or stagnated pollen-tube populations resulting from scramble competition for style resources (e.g. Harder, Aizen, \& Richards, 2016). Moreover, because honeybees are not necessarily efficient pollinators of some crops or crop production may depend on different pollinator species, it is not expected that honeybees by themselves are able to maximize crop yield (Garibaldi et al., 2013, 2016; Grass et al., 2018; Maclnnis \& Forrest, 2019).

Apple Malus domestica, Rosaceae is a high value, pollinatordependent crop (great dependence according to Klein et al., 2007) as it is highly self-incompatible and requires cross-pollination between different cultivars to increase crop yield (Modlibowska, 1945; Ramírez \& Davenport, 2013). Several wild bees, including native bumblebees (Bombus spp.) and solitary bees (e.g. Osmia sp.), as well as hoverflies have been described as efficient pollinators of apples (Földesi et al., 2016; Ramírez \& Davenport, 2013). Argentina is one of the 15 main apple producers and exporters in the world, and therefore, this crop represents an important source of economic income (FAO, 2018). Yet, typical commercial Argentinian apple orchards are characterized by a low abundance of wild pollinators, probably due to intensive crop management and use of pesticides (Geslin, Aizen, et al., 2017). For example, a previous study reported a complete absence of wild visitors in several orchards located in Neuquén Province, one of the most productive areas of the country (Geslin, Aizen, et al., 2017). One of the missing species is the black bumblebee Bombus pauloensis (sin. Bombus atratus; Sasal, 2016). This native species is widespread in South America, including the apple region of Neuquén as part of its historical southern range (Abrahamovich, Díaz, \& Lucia, 2007). This bumblebee species has been identified as an efficient pollinator of different crops such as tomatoes, strawberries and peppers amongst others (Aldana, Cure, Almanza, Vecil, \& Rodríguez, 2007; PovedaCoronel, Riaño Jiménez, Aguilar Benavides, \& Cure, 2018; Riaño, Pacateque, Cure, \& Rodríguez, 2015), and has been reported as a floral visitor in apples (Abrahamovich, Tellería, \& Díaz, 2001). Whereas many studies have focused on the relationship between honeybee density or pollinator diversity and crop production (Garibaldi et al., 2013, 2016; Geslin, Aizen, et al., 2017; Maclnnis \& Forrest, 2019; Sáez et al., 2014), only a few have assessed the individual contribution of key native pollinator species in crop production. Furthermore, 
as far as we know, no study has evaluated the effect on production and economic cost for local farmers of losing a particular pollinator species such as the black bumblebee.

We assessed the potential impact of losing the native black bumblebee by experimentally manipulating the presence of bumblebee colonies and managed honeybee hives in apple orchards on (a) crop yield (b) quantity and quality of pollen deposition, and (c) economic outcome of Argentinean farmers. Given that bumblebees are efficient pollinators, and, functionally speaking, potentially complementary to honeybees, we hypothesize an increased crop yield and economic profit in farms hosting both colonies of bumblebees and honeybees.

\section{2 | MATERIALS AND METHODS}

\section{1 | Study sites and experimental design}

The experiment was carried out in the Alto Valle (Neuquén Province, Argentina), a region that produces most of the country's apples (85\%) (Geslin, Aizen, et al., 2017). We performed the pollination experiment from 16 to 24 September in 2016, which was the approximate bloom period for Red Delicious in this year. We focused on Red Delicious, the most representative apple variety cultivated in this region. This variety is mostly self-incompatible, thus relying entirely on animal pollinators for compatible pollen transfer between trees (Geslin, Aizen, et al., 2017).

The experimental design consisted of eight conventional apple orchards separated by at least one $\mathrm{km}$ from each other and extending over a distance of $20 \mathrm{~km}$ along the main road in the valley (centroid located at $38^{\circ} 35^{\prime} 09.6^{\prime \prime} \mathrm{S} 68^{\circ} 21^{\prime} 57.6^{\prime \prime} \mathrm{W}$ ) (see details in Geslin, Aizen, et al., 2017). We selected orchards with very similar abiotic (e.g. temperature, precipitation, soil characteristics, etc.) and biotic conditions (e.g. size and age of individual apple trees) in order to avoid potential confounding effects. The extremely low abundance of wild pollinators in apple orchards of the region (Geslin, Aizen, et al., 2017) allowed us to experimentally manipulate the abundance and composition of the bee assemblages. To do so, we placed honeybee hives in each experimental farm with a density of seven hives per hectare, the recommended density in the Alto Valle for apple pollination (Geslin, Aizen, et al., 2017). A total of 24 colonies of black bumblebees B. pauloensis were placed in half of the experimental farms with six colonies per orchard ( $M=7$ colonies per hectare) and $c .80$ workers per colony. They were provided by an Argentinian company that started breeding this species in captivity recently. The original idea of the study was to simulate realistic scenarios that are common among apple growers. In this sense, the introduction of honeybee colonies is a standard management practice, which is implemented by default by apple producers. Therefore, we decided to use this situation as our baseline scenario and avoid the scenario with bumblebees alone. In each orchard, we selected 1-ha plots and both honeybee hives and bumblebee colonies were deployed along one edge of the plots. Apple trees were planted in rows with the same variety
(Red Delicious), which was interdispersed with rows of the pollen donor variety. We chose five trees per plot from which to collect data (detailed below), which were located c. $3 \mathrm{~m}$ apart along a row that was located at least $15 \mathrm{~m}$ from the border of each plot. Individual trees were very similar in terms of height (c. $4 \mathrm{~m}$ ) and crop volume.

\subsection{Pollination treatments and visits}

On each focal tree, we applied four different pollination treatments following a two-by-two factorial design: (a) flowers exposed to insect pollination (IP); (b) flowers exposed to insect pollination and supplemented with pollen manually (IPS); (c) flowers excluded from all insects (IE), including potential wild pollinators; and (d) flowers excluded from insects but supplemented with pollen manually (IES). In the 'no pollen-supplemented' treatments (IP, IE), tagged flowers were either freely exposed to insects (IP) or excluded with a $2 \mathrm{~mm}$ sized mesh bag (IE) with no further manipulation. In the handpollinated treatments (IPS, IES), we applied pollen manually from the appropriate pollen donor variety of the same crop using a paint-brush on receptive stigmas of fully open flowers. We applied pollen manually from Granny Smith, an appropriate compatible variety to pollinate Red Delicious apple flowers. For each treatment, we marked 2-3 branches per tree with $4.2 \pm 1.2$ flowers/branch. Overall, we tagged a mean of $81 \pm 20$ flowers per tree.

Before blooming, we characterized the total flowering effort of each sampled tree. This was done by estimating the total number of buds per tree, which was calculated by averaging the number of buds for each of five branches and then multiplying this value for the number of branches of each individual tree. We monitored each orchard four times throughout the flowering period and visited the orchard at different times of the day (from $09.00 \mathrm{hr}$ to $19.00 \mathrm{hr}$ ). In order to estimate visit rates of both honeybees and bumblebees in crop flowers, we surveyed bees along four 100-m linear walks throughout each plot, which were separated 20-30 m from each other. In order to standardize the sampling effort, each $100 \mathrm{~m}$-walk was subdivided into three sections of $1 \mathrm{~min}$ of observation with a constant walk speed (i.e. a total of 3 min for each $100 \mathrm{~m}$-walk transect). Given the absence of wild pollinators in our experimental orchards (see also Geslin, Aizen, et al., 2017) and the high detectability of the two large-sized species, which are also easy to distinguish because of colour and size differences, we firmly believe that this sampling design is appropriate to accurately estimate the abundance of visitors in apple flowers. In order to account for the potential effect of sun orientation and shadow area in the plot, we did side-focused observations with two of the walks surveying bees on the left, and two on the right side of the orchard row. The number of observed flower-visiting bees (i.e. the presence of a bee on a flower) was counted and identified as 'honey bee' Apis mellifera or 'bumble bee' Bombus pauloensis. Overall, we conducted 108 $100 \mathrm{~m}$-walking transects during the whole season.

A chemical thinner was applied to apple trees at the end of the fruiting season to stimulate the dropping of misshapen fruits. 
It is important to note that thinning does not affect randomly apples but selectively triggers the drop of worse-pollinated fruits. In addition, all orchards were conventionally managed, i.e. with intensive use of herbicides, fungicides and insecticides (see Geslin, Aizen, et al., 2017 for more information) for avoiding potential damages by pests and pathogens on fruit production. In late February and early March, after chemical thinning and just before the harvest period, we counted the number of ripe fruits per tagged branches and estimated the ratio of ripe fruits to floral buds, hereafter (fruit set), the number of fruits per tree, and collected fruits. Fruit weight was assessed during the following four days after harvest. We weighed each fruit $(n=283)$ with an electronic scale ( $0.1 \mathrm{~g}$ resolution) to assign them to a price category (see below for details). Finally, we counted the number of developed seeds for all collected fruits.

\subsection{Pollen deposition and pollen tubes}

When the flowers were no longer receptive, we collected apple styles in $70 \%$ ethanol solution, and kept them for subsequent laboratory analyses. The styles were washed with distilled water and prepared with aniline blue solution (Martin, 1959) in order to be observed under an epifluorescence microscope. The number of pollen grains deposited on the stigmas and the number of pollen tubes that reached the bottom part of styles were counted for each treatment and tree $(n=346)$.

\subsection{Statistical analysis}

\subsection{1 | Flower-visiting bee abundance}

Differences in abundance of honeybees and bumblebees visiting apple flowers were tested with a GLMM with a negative binomial error structure. The abundance of flower-visiting insects per transect was modelled in response of the bee species (honeybee vs. bumblebee) with farm identity included as a random factor. Distributions of residuals were inspected to check the assumptions of the models.

\subsection{2 | Fruit set, pollen deposition, growth of pollen tubes and seed development}

For assessing differences in (a) fruit set, (b) number of pollen grains deposited in stigmas, (c) number of pollen tubes that grew along the style, and (d) number of developed seeds among pollination treatments and between farms hosting bumblebees and honeybees and farms hosting only honeybees we performed a set of GLMMs. The above-mentioned variables were used as responses whereas pollination treatment (IP, IPS, IE, IES) and the presence of bumblebees and its interaction were incorporated as fixed effects, and farm as a random effect. We used a
Gaussian error structure for fruit set, a Poisson error structure for the number of pollen grains and the number of pollen tubes, and a negative binomial for the number of developed seeds to account for overdispersion. Differences between different levels of the fixed effects were evaluated with a posteriori multiple pairwise comparison (Tukey's HSD test). Finally, we assessed the relationships between the number of developed seeds and pollen tubes in both types of farms by applying a GLMM with the number of seeds as response variable and the presence of bumblebees, the number of pollen tubes and its interaction as fixed effects and the identity of the farm as a random factor. All analyses were performed with the glmmTMB (Brooks et al., 2017) and emmeans (Lenth, 2018) statistical packages in $R(R$ Core Team, 2018).

\subsection{3 | Farmer's profit}

We estimated the profit of farmers from apples in the two types of farms (with honeybees vs. with honeybees and bumblebees). Fruit price ranged according to three individual weight categories (small: <130 g; medium: 130-170 g; large: >170 g). The prices were 0.38, 0.66 and 0.80 \$USD/kg for small, medium and large apples respectively (Geslin, Aizen, et al., 2017). We estimated at the farm level the proportion of harvested fruits that belong to each of the three weight categories. The average costs associated with the farm inputs, excluding the price of honeybee and bumblebee colonies, were 0.28 \$USD $/ \mathrm{kg}$ and approximately $80 \%$ of apple production was sold. All economic data was estimated by Geslin, Aizen, et al. (2017) for the same area in the previous year (2015), and thus, we used the same cost structure. Changes in market price between both years (previous and sampling year) are not expected to influence the conclusions of our results as we were interested in assessing the relative difference between both types of farms rather than absolute gains of farmers per hectare. Following a similar framework of that of Geslin, Aizen, et al. (2017), we estimated the farmer incomes as follows:

Apple profit:f $\cdot d \cdot 0.8(s \cdot p \cdot \mathrm{ws}+m \cdot p \cdot \mathrm{wm}+l \cdot p \cdot \mathrm{wl})-(\mathrm{hcol} \cdot h+\mathrm{bcol} \cdot b)$

$-f \cdot d \cdot 0.8 \cdot 0.28 \cdot(s \cdot w s+m \cdot w m+l \cdot w l)$,

where $f=$ number of fruits per tree; $d=$ number of trees per hectares; $s=$ proportion of fruits in the small-sized category; $p=$ price of small-, medium- or large-sized category; ws = mean weight of smallsized fruits; $m=$ proportion of fruits in the medium-sized category; $\mathrm{wm}=$ mean weight of medium-sized fruits; $I$ = proportion of fruits in the large-sized category; $\mathrm{wl}=$ mean weight of large-sized fruits; hcol $=$ number of honeybee colonies installed per hectare; $h=$ rental price of a honeybee colony (20 US\$ per colony); bcol = number of bumblebee colonies installed per hectare; $b=$ acquisition price of a bumblebee colony (50 US\$ per colony).

We tested the potential effect of the loss of bumblebees on the profit of farmers in apple orchards by applying a Wilcoxon nonparametric test to compare farms with and without bumblebees. 


\section{3 | RESULTS}

The number of visits of honeybees per transect in apple flowers $(M \pm S D, 61.7 \pm 6.1)$ was almost two orders of magnitude higher $(Z=8.9, p<.05)$ than the visits of bumblebees $(0.9 \pm 0.3)$ in farms where bumblebees were introduced (Figure 1). In farms where bumblebees were not introduced, only honeybees visited the apple flowers (57.1 \pm 13.03 ) (Figure 1). No statistical differences were found in the number of honeybees visiting apple flowers between both types of farms $(Z=0.65, p>.05$; Figure 1$)$.

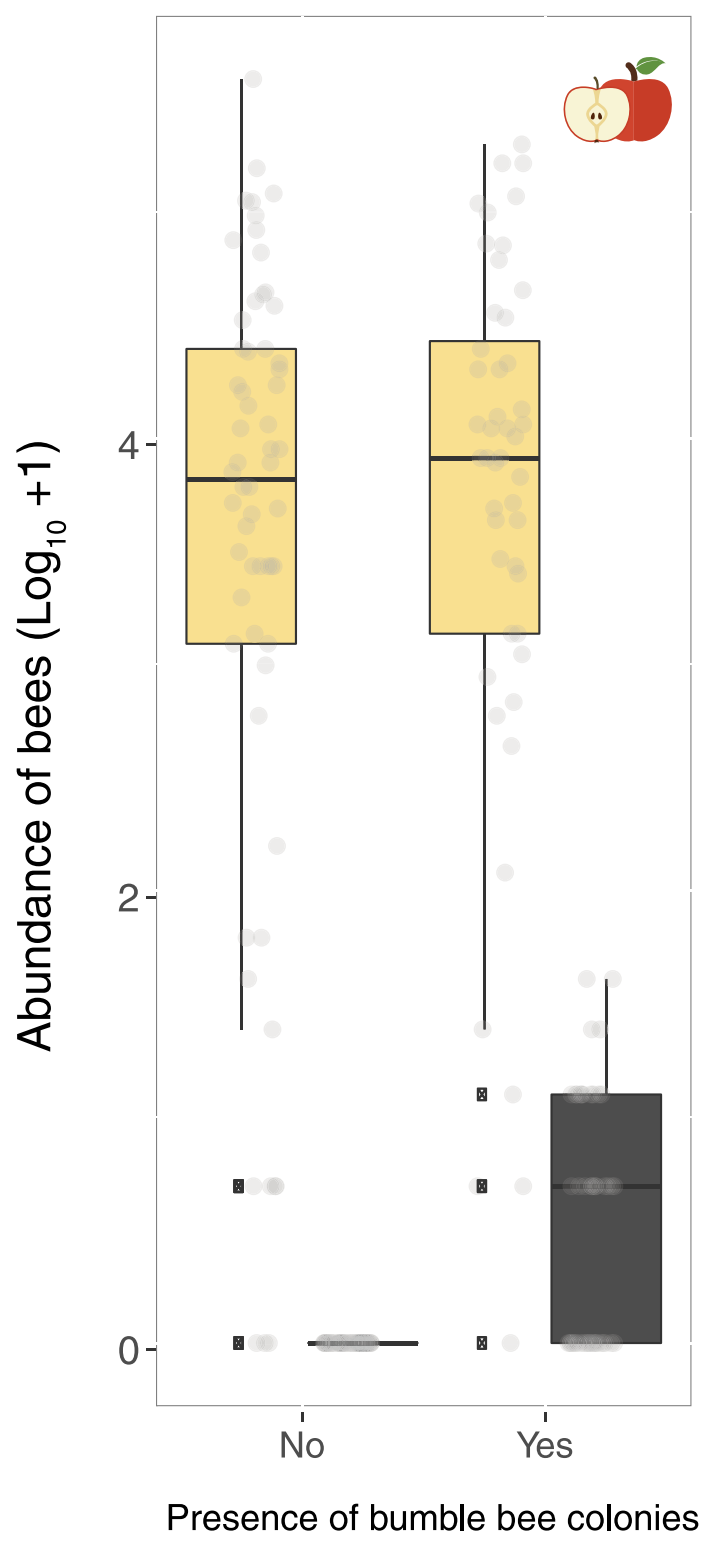

FIGURE 1 Abundance (bees per transect) of honeybees Apis mellifera (yellow boxes) and the native black bumblebees Bombus pauloensis (grey boxes) visiting flowers in apple orchards at farms where colonies of bumblebees have been introduced (Yes) and farms where colonies of black bumblebees have not been introduced (No). Grey dots represent transects, boxes show the inter-quartile range (IQR), horizontal line represent the median, whiskers show the range of $1.5 \times$ IQR. Icons: www.freepik.com
Fruit set in flowers that were exposed to insect pollination (IP and IPS) was more than two-fold higher in farms with bumblebees and honeybees than in farms hosting honeybees only (IP: $t=-3.91$, $p<.01$, IPS: $t=-2.50, p<.01$ ) (Figure 2a). Flowers excluded from insect pollination (IE and IES) showed lower fruit set than flowers exposed to pollinators (IP and IPS) (see Figure 2a for the rest of comparisons). Fruit set in treatment IPS (insect access and pollen supplementation) was higher than in treatment IES (exclusion from insects and pollen supplementation), but only in farms where bumblebees were introduced $(t=2.89 ; p=.07)$.

Both the number of pollen grains deposited on stigmas and the number of pollen tubes that reached the bottom section of styles in flowers exposed to insect pollination (IP and IPS) in farms hosting bumblebees were not statistically different from farms that hosted only honeybees (Figure $2 b, c)$. Unexpectedly, the number of pollen grains in the IP treatment (insect pollination, non-supplemented) was higher than in the IPS treatment (insect pollination, supplemented). As expected, fruit set, pollen deposition and pollen tubes in IE treatment (insect exclusion, non-supplemented) were lower $(p<.01)$ than in the rest of treatments (Figure 2). The number of pollen grains was positively associated to the number of pollen tubes that reached the bottom of the styles $(Z=2.05, p<.05)$. Yet this relationship was very similar in both types of farms ( $Z=1.01, p>.05$; Figure 3a).

The number of developed seeds was higher in farms hosting bumblebees than in farms hosting only honeybees $(Z=3.319, p<.05$, Figure $3 b)$. Additionally, the number of developed seeds showed a positive relationship with pollen tubes only in farms lacking bumblebees $(Z=2.45, p<.05$, Figure $3 c)$. In this sense, the number of developed seeds in farms without bumblebees only reached the values of farms with bumblebees in situations where the number of pollen tubes was high (Figure 3c).

Number of fruits per tree and farmer profit (i.e. farmer income after deduction of production costs and colony rentals) was 4-fold and 2.4-fold lower $(W=14, p<.05)$ in farms lacking the native bumblebee species (Figure 4), respectively. The average profit in these farms was 6,774 $\pm 1,533$ \$USD/ha, while farmers who installed colonies of both pollinator groups earned 16,302 $\pm 5,072 \$$ USD/ha (Figure 4b).

\section{4 | DISCUSSION}

Loss of key native pollinator species may not only have negative consequences on ecosystem functionality, but also on crop production (Potts et al., 2010). Here we demonstrate that fruit set of apple farmers is reduced in the absence of native bumblebees. Interestingly, bumblebees did not increase pollen deposition and the formation of pollen tubes beyond that observed for honeybees alone. However, the higher success of pollination in terms of seed development observed in flowers exposed to bumble bee visitation suggests that benefits provided by this species might be mediated by changes in the quality of pollen they transfer (Aizen \& Harder, 2007). Reduced fruit set in apples translated to decreased crop yields, causing an important reduction in the farmer's economic benefits. 

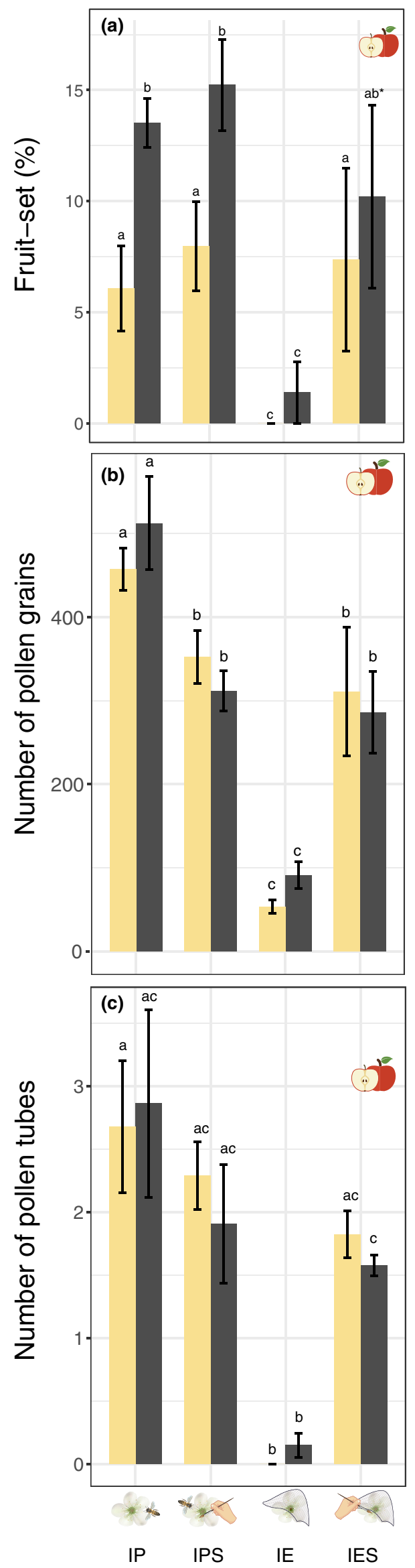

FIGURE 2 Effects of pollination treatments (IP, IPS, IE, IES) on ripe fruit set (panel a), pollen deposition (panel b) and growth of pollen tubes (panel c) $(M \pm S E)$ on farms hosting honeybees Apis mellifera and the native black bumblebees Bombus pauloensis (grey bars) and farms hosting only honeybees (yellow bars). Same letters indicate no statistical differences between treatments. Asterisks $\left.{ }^{*}\right)$ indicate marginal statistical differences between treatments $(p=.07)$. Icons: www.freepik.com

The exclusion of apple flower visitors reduced fruit set drastically (Figure 2a), which confirms that apple is highly dependent on animal-mediated pollination (Klein et al., 2007). The most common management practice used to increase yield of pollinator-dependent crops consists in adding high amounts of honeybees (Aebi et al., 2012; Goodwin et al., 2011; Rucker et al., 2012). However, recent evidence shows that honeybees, even when present at high abundances, are not able to close yield gaps when other wild pollinators that complement crop pollination are not present (Garibaldi et al., 2013; MacInnis \& Forrest, 2019). Fruit set of apples was reduced by more than half in farms with high densities of honeybees but lacking native bumblebees compared to farms with both pollinator groups. These differences are not attributable to differences in honeybee visitation rates between the two types of farms as density of beehives introduced was the same and the abundance of foraging honeybees was quite similar. In addition, flowers that were excluded from pollinators after being supplemented manually with pollen (treatment IES) showed a 5\% lower fruit set compared to those that were supplemented and exposed to insect pollination (treatment IPS). Interestingly, this pattern only occurred in farms where both honeybees and bumblebees were present, suggesting that pollen and/or flower handling by bumblebees has an important positive effect on fruit set. We have to interpret this last result with caution as the $p$-value associated to the statistical model was just marginally significant $(p=.07)$.

The increased fruit set in apples on farms with bumblebees cannot be attributed to an increase of pollen grains received by stigmas, or in the number of pollen tubes that reached the bottom of the style. Pollen deposition and tube growth showed high variability, and no statistical differences were found between farms hosting both pollinator species and farms hosting only honeybees. Therefore, the most parsimonious explanation to the differences in fruit set could be attributed to differences in the quality of pollen transferred by the two species. In this sense, the number of developed seeds was low in farms where the bumblebees were absent. Apples showed a high number of developed seeds (i.e. similar to apples harvested in farms with bumblebees) only when the number of pollen tubes increased considerably (see Figure $3 c$ ). This suggests that each single pollen grain deposited (and pollen tube growing) in bumblebee-exposed flowers has a higher probability of fertilizing an ovule and bearing a seed than pollen grains deposited in flowers exposed only to honeybees.

Foraging behaviour of both species could account for these differences. Honeybees usually move between trees less frequently and 
FIGURE 3 (a) Relationship between the number of pollen grains deposited and the number of pollen tubes that reached the bottom section of the style of apple flowers in orchards hosting honeybees Apis mellifera and the native black bumblebees Bombus pauloensis (grey) and orchards hosting only honeybees (yellow). (b) Number of developed seeds of apples from flowers exposed to pollinators (IP treatment) in both types of apple orchards. (c) Relationship between the number of pollen tubes that reached the bottom section of the style and the number of developed seeds in both types of apple orchards. Icons: www.freep ik.com

FIGURE 4 Number of fruits per tree (a) and farmer's net income in \$USD per hectare $(M \pm S E)(b)$ in apple orchards where colonies of bumblebees have been introduced (Yes, grey bars) and farms where colonies have not been introduced (No, yellow bars). Icons: www.freepik.com
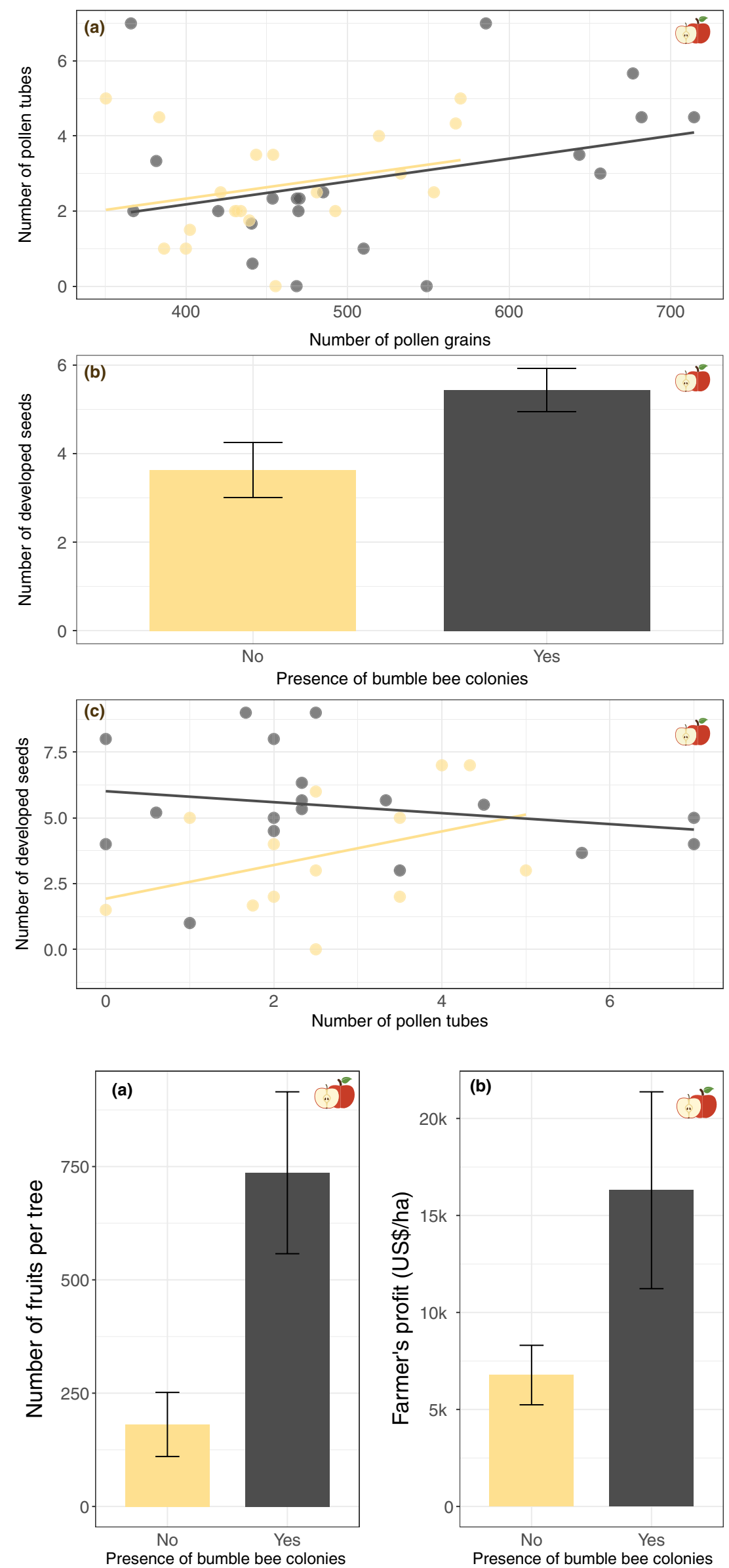
over shorter distances than bumblebees (Dupont, Hansen, Valido, \& Olesen, 2004; McBrydie, Howlett, \& Pattemore, 2017; but see Miñarro \& García, 2018; Palmer-Jones \& Clinch, 1966), thus, promoting geitonogamy (i.e. pollen transfer among flowers of the same individual). This is expected to reduce outcrossing (e.g. Whelan, Ayre, \& Beynon, 2009), activating late-acting pre-zygotic or post-zygotic barriers that reject self pollen (Seavey \& Bawa, 1986), even when pollen deposition is high. Several studies performed in both natural and agricultural ecosystems have also shown a low production of seeds in contexts where honeybee density is very high and dominates the assemblage of pollinators (Rollin \& Garibaldi, 2019; Valido, Rodríguez-Rodríguez, \& Jordano, 2019).

Insect pollination has a high market value in apple production as suggested previously (Garratt et al., 2014; Geslin, Aizen, et al., 2017) and confirmed by our results. In our experimental farms, honeybee pollination provides an average net income of 6,774 \$USD/ha to apple farmers. This economic performance is unexpectedly lower than the values reported by Geslin, Aizen, et al. (2017) in the previous years, who found a mean profitability per hectare of 12,080 \$USD/ ha. Given that we used the same experimental farms, we expected a similar mean profitability in apple orchards as that reported by Geslin, Aizen, et al. (2017). Inter-annual differences in abiotic conditions and/ or management practices could explain this result as these factors may modify potential crop yield across years (Lobell, Cassman, \& Field, 2009). Yet we found that mean profitability in farms where bumblebees were additionally introduced was 30\% higher (16,302 \$USD/ha) than those reported by Geslin, Aizen, et al. (2017). This result would highlight the importance of promoting insect diversity in productive landscapes, as the impact of climatologically unfavourable years on crop yield could be buffered by the presence of pollinators with different susceptibility to adverse climatic conditions. Differences in the quality of beehives introduced, which has been identified as a critical factor influencing crop yield (Geslin, Aizen, et al., 2017), could also explain the pattern found. We hypothesized that biodiversity loss at farm scale would reduce crop productivity and economic profit of farmers (Garibaldi et al., 2013; Rader et al., 2016). Accordingly, we found that losing a single key species such as the native black bumblebee reduced the economic performance by more than half in apple orchards. Profits in farms hosting two pollinator groups are still slightly low when compared with more biodiverse apple farms (Garratt et al., 2014), suggesting that, by enhancing pollinator diversity, there is still room for increasing profitability in our depauperate farms.

\section{5 | CONCLUSIONS}

Anthropogenic impacts are triggering unprecedented rates of wild pollinator declines (González-Varo et al., 2013; Goulson et al., 2015; Vanbergen et al., 2013) with negative consequences for ecosystem functioning and crop production (Potts et al., 2010). Our results show that crop yield and farmer's profit might be reduced drastically after the disappearance of a key functional group, even when abundance of managed honeybees is high. This emphasizes the importance of properly managing farms in order to meet the rising demand of food while conserving the full range of wild pollinator species. Adopting pollinator-friendly practices at farm and landscape scales (Garibaldi et al., 2019) will have the double advantage of promoting biodiversity conservation and increasing crop productivity and profitability. Yet because ecologically intensive practices can take time to deliver results (e.g. enhance pollinator diversity and abundance) (Garibaldi et al., 2019), the management of native pollinator species, such as in the Alto Valle, can be a provisional complementary strategy to increase economic profitability of apple growers in the short term.

\section{ACKNOWLEDGEMENTS}

We thank P. Hünicken for assistance with database management and for providing valuable information about the study system. We are also indebted to the owners and managers of the farms, who provided us with all the facilities to perform this study. Funding was provided by Consejo Nacional de Investigaciones Científicas y Técnicas (PDTS, Res 298/14, Exp 8383/13) and Universidad Nacional de Río Negro (PI 40-B-399 and PI 40-B-567) and the National Fund for Research (PICT 2015-2333). We acknowledge Brometan for providing the bumblebee colonies. The manuscript benefited from constructive comments of J.P González-Varo.

\section{AUTHORS' CONTRIBUTIONS}

All authors conceived the idea and designed the study. G.K.S.A., F.R., J.H. and N.G. collected the data. J.H. and G.K.S.A. performed the laboratory analysis. N.P.-M. analysed the data with substantial inputs from L.A.G., G.K.S.A. and M.A.A., and wrote a first draft of the manuscript. All authors contributed critically to the drafts and gave final approval for publication.

\section{DATA AVAILABILITY STATEMENT}

Data available via the figshare https://doi.org/10.6084/m9.figsh are.10282958.v2 (Pérez-Méndez et al., 2019).

\section{ORCID}

Néstor Pérez-Méndez (iD https://orcid.org/0000-0001-6264-2920 Georg K. S. Andersson (iD https://orcid.org/0000-0002-9669-6895 Fabrice Requier iD https://orcid.org/0000-0003-1638-3141 Juliana Hipólito iD https://orcid.org/0000-0002-0721-3143 Marcelo A. Aizen (iD https://orcid.org/0000-0001-9079-9749 Carolina L. Morales (ID https://orcid.org/0000-0002-9989-5347 Gerardo P. Gennari (iD https://orcid.org/0000-0001-5204-2032 Lucas A. Garibaldi iD https://orcid.org/0000-0003-0725-4049

\section{REFERENCES}

Abrahamovich, A. H., Díaz, N., \& Lucia, M. (2007). Identificación de las "abejas sociales" del género Bombus (Hymenoptera: Apidae) presentes en la Argentina: Clave pictórica, diagnosis, distribución geográfica y asociaciones florales. Revista De La Facultad De Agronomía, 106(2), 165-176. https://doi.org/10.1016/0006-8993(73)90146-7

Abrahamovich, A. H., Tellería, M. C., \& Díaz, N. B. (2001). Bombus species and their associated flora in Argentina. Bee World, 82(2), 76-87. https:// doi.org/10.1080/0005772X.2001.11099505 
Aebi, A., Vaissière, B. E., van Engelsdorp, D., Delaplane, K. S., Roubik, D. W., \& Neumann, P. (2012). Back to the future: Apis versus non-Apis pollination: A response to Ollerton et al. Trends in Ecologyand Evolution, 27(3), 142-143. https://doi.org/10.1016/j.tree.2011.11.017

Aizen, M. A., Garibaldi, L. A., Cunningham, S. A., \& Klein, A. M. (2009). How much does agriculture depend on pollinators? Lessons from long-term trends in crop production. Annals of Botany, 103(9), 15791588. https://doi.org/10.1093/aob/mcp076

Aizen, M. A., \& Harder, L. D. (2007). Expanding the limits of the pollen-limitation concept: Effects of pollen quantity and quality. Ecology, 88(2), 271-281. https://doi.org/10.1890/06-1017

Aizen, M. A., \& Harder, L. D. (2009). The global stock of domesticated honey bees is growing slower than agricultural demand for pollination. Current Biology, 19(11), 915-918. https://doi.org/10.1016/j. cub.2009.03.071

Aldana, J., Cure, J. R., Almanza, M. T., Vecil, D., \& Rodríguez, D. (2007). Effect of Bombus atratus (Hymenoptera: Apidae) on tomato production (Lycopersicon esculentum Mill.) in greenhouse in Bogotá plateau. Colombia Johanna. Agronomia Colombiana, 25(1), 62-72.

Arbetman, M. P., Gleiser, G., Morales, C. L., Williams, P., \& Aizen, M. A. (2017). Global decline of bumblebees is phylogenetically structured and inversely related to species range size and pathogen incidence. Proceedings of the Royal Society B: Biological Sciences, 284(1859), 20170204. https://doi.org/10.1098/rspb.2017.0204

Bommarco, R., Lundin, O., Smith, H. G., \& Rundlöf, M. (2012). Drastic historic shifts in bumble-bee community composition in Sweden. Proceedings of the Royal Society B: Biological Sciences, 279(1727), 309315. https://doi.org/10.1098/rspb.2011.0647

Breno, M. F., Lúcia, V., Luis, M. M., Matos, A. D., Peixoto, K., Leonardo, G., ... Barthelemy, S. (2009). Diversity, threats and conservation of native bees in the Neotropics. Apidologie, 40, 332-346. https://doi. org/10.1051/apido/2009012

Brooks, M. E., Kristensen, K., Benthem, K. J., Magnusson, A., Berg, C. W., Nielsen, A., ... Bolker, B. M. (2017). glmmTMB balances speed and flexibility among packages for zero-inflated generalized linear mixed modeling. The R Journal, 8(2), 378-400. https://doi.org/10.32614/ RJ-2017-066

Dupont, Y. L., Hansen, D. M., Valido, A., \& Olesen, J. M. (2004). Impact of introduced honey bees on native pollination interactions of the endemic Echium wildpretii (Boraginaceae) on Tenerife, Canary Islands. Biological Conservation, 118(3), 301-311. https://doi.org/10.1016/j. biocon.2003.09.010

FAO. (2018). FAOSTAT. Food and Agriculture Organization of the United Nations. Retrieved from http://faostat.fao.org/site/377/defau It.aspx\#ancor

Földesi, R., Kovács-Hostyánszki, A., Kőrösi, Á., Somay, L., Elek, Z., Markó, V., ... Báldi, A. (2016). Relationships between wild bees, hoverflies and pollination success in apple orchards with different landscape contexts. Agricultural and Forest Entomology, 18(1), 68-75. https:// doi.org/10.1111/afe.12135

Garibaldi, L. A., Carvalheiro, L. G., Vaissiere, B. E., Gemmill-Herren, B., Hipolito, J., Freitas, B. M., ... Zhang, H. (2016). Mutually beneficial pollinator diversity and crop yield outcomes in small and large farms. Science, 351(6271), 388-391. https://doi.org/10.1126/scien ce.aac7287

Garibaldi, L. A., Pérez-Méndez, N., Garratt, M. P. D., Gemmill-Herren, B., Miguez, F. E., \& Dicks, L. V. (2019). Policies for ecological intensification of crop production. Trends in Ecology \& Evolution, 34(4), 282-286. https://doi.org/10.1016/j.tree.2019.01.003

Garibaldi, L. A., Requier, F., Rollin, O., \& Andersson, G. K. S. (2017). Towards an integrated species and habitat management of crop pollination. Current Opinion in Insect Science, 21, 105-114. https://doi. org/10.1016/j.cois.2017.05.016

Garibaldi, L. A., Steffan-Dewenter, I., Kremen, C., Morales, J. M., Bommarco, R., Cunningham, S. A., ... Klein, A. M. (2011). Stability of pollination services decreases with isolation from natural areas despite honey bee visits. Ecology Letters, 14(10), 1062-1072. https:// doi.org/10.1111/j.1461-0248.2011.01669.x

Garibaldi, L. A., Steffan-Dewenter, I., Winfree, R., Aizen, M. A., Bommarco, R., Cunningham, S. A., ... Klein, A. M. (2013). Wild pollinators enhance fruit set of crops regardless of honey bee abundance. Science, 339(6127), 1608-1611. https://doi.org/10.1126/ science. 1230200

Garratt, M. P. D., Breeze, T. D., Jenner, N., Polce, C., Biesmeijer, J. C., \& Potts, S. G. (2014). Avoiding a bad apple: Insect pollination enhances fruit quality and economic value. Agriculture, Ecosystems and Environment, 184, 34-40. https://doi.org/10.1016/j. agee.2013.10.032

Geslin, B., Aizen, M. A., Garcia, N., Pereira, A.-J., Vaissière, B. E., \& Garibaldi, L. A. (2017). The impact of honey bee colony quality on crop yield and farmers' profit in apples and pears. Agriculture, Ecosystems and Environment, 248, 153-161. https://doi.org/10.1016/j. agee.2017.07.035

Geslin, B., Gauzens, B., Baude, M., Dajoz, I., Fontaine, C., Henry, M., ... Vereecken, N. J. (2017). Massively introduced managed species and their consequences for plant-pollinator interactions. Advances in Ecological Research, 57, 147-199. https://doi.org/10.1016/ bs.aecr.2016.10.007

González-Varo, J. P., Biesmeijer, J. C., Bommarco, R., Potts, S. G., Schweiger, O., Smith, H. G., ... Vilà, M. (2013). Combined effects of global change pressures on animal-mediated pollination. Trends in Ecology \& Evolution, 28(9), 524-530. https://doi.org/10.1016/j. tree.2013.05.008

Goodwin, R., Cox, H., Taylor, M., Evans, L., \& McBrydie, H. (2011). Number of honey bee visits required to fully pollinate white clover (Trifolium repens) seed crops in Canterbury, New Zealand. New Zealand Journal of Crop and Horticultural Science, 39(1), 7-19. https:// doi.org/10.1080/01140671.2010.520164

Goulson, D., Nicholls, E., Botías, C., \& Rotheray, E. L. (2015). Bee declines driven by combined stress from parasites, pesticides, and lack of flowers. Science, 347(6229), 1255957. https://doi.org/10.1126/scien ce.1255957

Grass, I., Meyer, S., Taylor, P. J., Foord, S. H., Hajek, P., \& Tscharntke, T. (2018). Pollination limitation despite managed honeybees in South African macadamia orchards. Agriculture, Ecosystems and Environment, 260, 11-18. https://doi.org/10.1016/j.agee.2018.03.010

Harder, L. D., Aizen, M. A., \& Richards, S. A. (2016). The population ecology of male gametophytes: The link between pollination and seed production. Ecology Letters, 19(5), 497-509. https://doi.org/10.1111/ ele.12596

Javorek, S. K., Mackenzie, K. E., \& Vander Kloet, S. P. (2002). Comparative pollination effectiveness among bees (Hymenoptera: Apoidea) on lowbush blueberry (Ericaceae: Vaccinium angustifolium). Annals of the Entomological Society of America, 95(3), 345-351. https://doi. org/10.1603/0013-8746(2002)095[0345:CPEABH]2.0.CO;2

Klein, A.-M., Vaissiere, B. E., Cane, J. H., Steffan-Dewenter, I., Cunningham, S. A., Kremen, C., \& Tscharntke, T. (2007). Importance of pollinators in changing landscapes for world crops. Proceedings of the Royal Society B: Biological Sciences, 274(1608), 303-313. https:// doi.org/10.1098/rspb.2006.3721

Lenth, R. (2018). emmeans: Estimated marginal means, aka least-squares means. R package version 1.1.3. Retrieved from https://CRAN. R-project.org/package=emmeans

Lobell, D. B., Cassman, K. G., \& Field, C. B. (2009). Crop yield gaps: Their importance, magnitudes, and causes. NCESR Publications and Research, 34, 179-204. https://doi.org/10.1146/annurevfie nviron.041008.093740

Maclnnis, G., \& Forrest, J. R. K. (2019). Pollination by wild bees yields larger strawberries than pollination by honey bees. Journal of Applied Ecology, 56(4), 824-832. https://doi.org/10.1111/1365-2664.13344 
Martin, F. W. (1959). Staining and observing pollen tubes in the style by means of fluorescence. Stain Technology, 34(3), 125-128. https://doi. org/10.3109/10520295909114663

Martins, A. C., \& Melo, G. A. R. (2010). Has the bumblebee Bombus bellicosus gone extinct in the northern portion of its distribution range in Brazil? Journal of Insect Conservation, 14(2), 207-210. https://doi. org/10.1007/s10841-009-9237-y

McBrydie, H. M., Howlett, B. G., \& Pattemore, D. E. (2017). Relative abundance and movement of flower visitors within "Black Doris" plum orchards in Hawke's Bay, New Zealand. New Zealand Plant Protection, 70, 58-62. https://doi.org/10.1016/j.im.2016.11.008

Miñarro, M., \& García, D. (2018). Complementarity and redundancy in the functional niche of cider apple pollinators. Apidologie, 49(6), 789802. https://doi.org/10.1007/s13592-018-0600-4

Modlibowska, I. (1945). Pollen tube growth and embryo-sac development in apples and pears. Journal of Pomology and Horticultural Science, 21(1-4), 57-89. https://doi.org/10.1080/03683621.1945. 11513615

Morales, C. L., Arbetman, M. P., Cameron, S. A., \& Aizen, M. A. (2013). Rapid ecological replacement of a native bumble bee by invasive species. Frontiers in Ecology and the Environment, 11(10), 529-534. https:// doi.org/10.1890/120321

Palmer-Jones, T., \& Clinch, P. G. (1966). Observations on the pollination of apple trees (Malus sylvestris Mill.). New Zealand Journal of Agricultural Research, 9(2), 191-196. https://doi.org/10.1080/00288 233.1966.10420773

Pérez-Méndez, N., Andersson, G., Requier, F., Hipólito, J., Aizen, M., Morales, C., ... Garibaldi, L. A. (2019). Data-set: The economic cost of losing native pollinator species for orchard production (version 1). Figshare, https://doi.org/10.6084/m9.figshare.10282958.v2

Potts, S. G., Biesmeijer, J. C., Kremen, C., Neumann, P., Schweiger, O., \& Kunin, W. E. (2010). Global pollinator declines: Trends, impacts and drivers. Trends in Ecology and Evolution, 25(6), 345-353. https://doi. org/10.1016/j.tree.2010.01.007

Potts, S. G., Imperatriz-Fonseca, V., Ngo, H. T., Aizen, M. A., Biesmeijer, J. C., Breeze, T. D., ... Vanbergen, A. J. (2016). Safeguarding pollinators and their values to human well-being. Nature, 540(7632), 220-229. https://doi.org/10.1038/nature20588

Potts, S. G., Imperatriz-Fonseca, V. L., Ngo, H. T., Biesmeijer, J. C., Breeze, T. D., Dicks, L. V., ... Viana, B. F. (2016). IPBES (2016): Summary for policymakers of the assessment report of the Intergovernmental Science-Policy Platform on Biodiversity and Ecosystem Services on pollinators, pollination and food production. Bonn, Germany: Secretariat of the Intergovernmental Science-Policy Platform on Biodiversity and Ecosystem Services. https://doi.org/10.1371/journ al.pone.0090102

Poveda-Coronel, C. A., Riaño Jiménez, D., Aguilar Benavides, L., \& Cure, J. R. (2018). Eficiencia de polinización de colonias huérfanas del abejorro nativo Bombus atratus (Hymenoptera: Apidae) en dos cultivares de fresa (Fragaria $x$ ananassa) sembrados bajo cubierta en la sabana de Bogotá. Acta Biológica Colombiana, 23(1), 73-79. https:// doi.org/10.15446/abc.v23n1.61648

R Core Team. (2018). R: A language and environment for statistical computing. Vienna, Austria: R Foundation for Statistical Computing.
Rader, R., Bartomeus, I., Garibaldi, L. A., Garratt, M. P. D., Howlett, B. G., Winfree, R., ... Woyciechowski, M. (2016). Non-bee insects are important contributors to global crop pollination. Proceedings of the National Academy of Sciences of the United States of America, 113(1), 146-151. https://doi.org/10.1073/pnas.1517092112

Ramírez, F., \& Davenport, T. L. (2013). Apple pollination: A review. Scientia Horticulturae, 162, 188-203. https://doi.org/10.1016/j.scien ta.2013.08.007

Riaño, J. D., Pacateque, E. J., Cure, J. R., \& Rodríguez, D. (2015). Comportamiento y eficiencia de polinización de Bombus atratus Franklin en pimentón (Capsicum annum L.) sembrado bajo invernadero. Revista Colombiana De Ciencias Hortícolas, 9(2), 259-267. https:// doi.org/10.17584/rcch.2015v9i2.4182

Rollin, O., \& Garibaldi, L. A. (2019). Impacts of honey bee density on crop yield: A meta-analysis. Journal of Applied Ecology, 56(5), 1152-1163. https://doi.org/10.1111/1365-2664.13355

Rucker, R. R., Thurman, W. N., \& Burgett, M. (2012). Honey bee pollination markets and the internalization of reciprocal benefits. American Journal of Agricultural Economics, 94(4), 956-977. https:// doi.org/10.1093/ajae/aas031

Rundlöf, M., Andersson, G. K. S., Bommarco, R., Fries, I., Hederström, V., Herbertsson, L., ... Smith, H. G. (2015). Seed coating with a neonicotinoid insecticide negatively affects wild bees. Nature, 521(7550), 77-80. https://doi.org/10.1038/nature14420

Sáez, A., Morales, C. L., Ramos, L. Y., \& Aizen, M. A. (2014). Extremely frequent bee visits increase pollen deposition but reduce drupelet set in raspberry. Journal of Applied Ecology, 51(6), 1603-1612. https:// doi.org/10.1111/1365-2664.12325

Sasal, Y. (2016). Bombus atratus. The IUCN Red List of Threatened Species 2016: e.T21215147A21215173. https://doi.org/10.2305/ IUCN.UK.2016-1.RLTS.T21215147A21215173.en

Seavey, S. R., \& Bawa, K. S. (1986). Late-acting self-incompatibility in angiosperms. Botanical Review, 52(2), 195-219. https://doi. org/10.1007/BF02861001

Valido, A., Rodríguez-Rodríguez, M. C., \& Jordano, P. (2019). Honeybees disrupt the structure and functionality of plant-pollinator networks. Scientific Reports, 9(1), 4711. https://doi.org/10.1038/s41598019-41271-5

Vanbergen, A. J., Garratt, M. P., Vanbergen, A. J., Baude, M., Biesmeijer, J. C., Britton, N. F., ... Wright, G. A. (2013). Threats to an ecosystem service: Pressures on pollinators. Frontiers in Ecology and the Environment, 11(5), 251-259. https://doi.org/10.1890/120126

Whelan, R. J., Ayre, D. J., \& Beynon, F. M. (2009). The birds and the bees: Pollinator behaviour and variation in the mating system of the rare shrub Grevillea macleayana. Annals of Botany, 103(9), 1395-1401. https://doi.org/10.1093/aob/mcp091

How to cite this article: Pérez-Méndez N, Andersson GKS, Requier $\mathrm{F}$, et al. The economic cost of losing native pollinator species for orchard production. J Appl Ecol. 2020;00:1-10. https://doi.org/10.1111/1365-2664.13561 